\title{
The Impact of the Culture on User's Emotional Response
}

\author{
Fekry Gamal $^{1}$, Abd Elnaby Abo Elmagd ${ }^{1}$, Tamer Yousif ${ }^{2}$ \\ ${ }^{1}$ Industrial Design Department, Helwan University, Cairo, Egypt \\ ${ }^{2}$ Industrial Engineering Department, Canadian International College for Engineering, Cairo, Egypt
}

Email address:

Tameryousif10@yahoo.com (T. Yousif)

\section{To cite this article:}

Fekry Gamal, Abd Elnaby Abo Elmagd, Tamer Yousif. The Impact of the Culture on User's Emotional Response. American Journal of Applied Psychology. Vol. 7, No. 3, 2018, pp. 44-49. doi: 10.11648/j.ajap.20180703.11

Received: May 8, 2018; Accepted: June 21, 2018; Published: July 11, 2018

\begin{abstract}
The main interest of the industrial designer has become acquiring user's satisfaction. One example of this interest is studying the cultural environment of the society that users live in. And how the culture would affect user's usage behavior, acceptance and emotional responses to the product. Cultural values play an essential role in every human life aspect. Moreover, supposedly, the growing of the industrial design is not excluded from the existing cultural influences. Since culture generally affects the interactions between people, it also influences the way people deal with products. Many Researchers have considered how different emotions relate to the perception of same product design from different cultural background users. This paper assumes that different cultural elements have an impact on the user's emotional response. So, This paper tries to show how the user's emotional response influenced by the user's culture. Alao, the industrial designer can benefit from the impact of the culture on user's emotional response to design a product matches the user's culture, and achieves the positive emotional response.
\end{abstract}

Keywords: Design for Emotion, Emotional Response, Cultural Factors, Culture Design

\section{Introduction}

Culture is the mainframe for human personality to grow. It reflects his information, thoughts, experiences and emotional responses expressions. There is no doubt that the cultural frame within the society that the human lives in is responsible for the variance of emotional responses. Thus, there are many differences in concepts and emotional responses when comparing between two different cultures.

In the era of globalization, opening markets, current economic variables and aiming to increase exports. Consumers satisfaction has become one the most important factors to success in the light of high competitions among global cooperates. Therefore, designing products for different global markets has now become a challenge for designers. This challenge is being harder with the spread of globalization. Because it leads to new huge numbers of consumers for the same product with different cultures and traditions, thus, have different expectations, product understanding, and emotional responses.

\section{Culture Concept}

Culture is a product made by human beings who meet together to establish a society. As there is no one can live alone, people are living together forming a society with a unique culture. It includes values, traditions, knowledge, arts, and beliefs that a person acquire as a member of his society. Culture gives everyone the ability to think about himself and has the distinctiveness of logical thinking. So, culture represents what relates to human nature.

\subsection{Culture Elements}

Some specialists such as Lenton urges that the cultural content of any homogeneous society consists of three main elements, figure 1. 


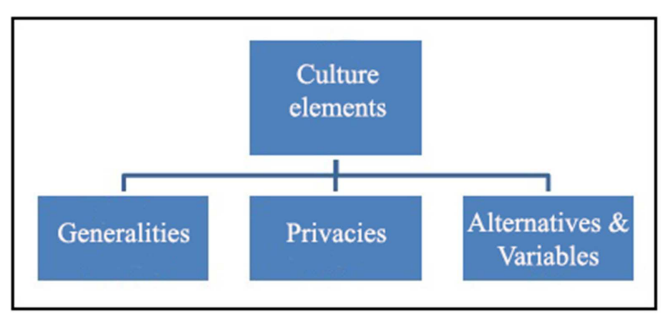

Figure 1. Culture elements.

\subsubsection{Generalities}

Generalities are the basis of culture, in which most members of a society participate. It outlines the character of each community. Examples of it include symbols, language, religion, values, customs and ways of thinking that distinguish the members of the same society. These generalities give culture its distinctiveness.

\subsubsection{Privacies}

Privacies is what relates to a specific group of people within the society. Examples of it include privacies that exist among members of certain professions, or among members of certain social strata. The rest of society has an idea about these privacies.

\subsubsection{Alternatives \& Variables}

The elements that feature recently in the society, and being introduced for the first time to society's culture. That includes new inventions in light of certain culture, work methods and non-stereotypical responses to similar situations. These elements are always unstable until become private or general.

\subsection{Culture in Product Design}

Culture plays an important role in product design field. Culture considerations in modern designs have become one of the designing methods in the global market. As the product design represents one of the outputs of the culture industry. Moreover, neglecting cultural considerations in designing a product would lead to the refusal of it by users. Thus, industrial designers have to be aware of how to include culture considerations while designing their product in order to enhance its identity in the global market.

Culture has an impact on designing the product, e.g. designing cars. Therefore, people choices differ from one country to another according to their culture. So buying cars is no longer an economic choice, but it is now more related to emotional values which are influenced by culture.

To avoid problems related to cultural differences among countries, many industrial organizations launch customized products for each country. For example, Ford company produced "Ford Fiesta" car and distributed it with different designs in many countries according to each country's cultural factors and different aesthetic sense of its citizens [11]. E.g., "Ford Fiesta" in Brazil (figure 2) and "Ford Fiesta" in India (figure 3). Ford company uses a unified strategy. But has launched the "Ford Fiesta" with different designs depending on factors specific to each country such as culture, social norms, driving rules, and regulations.

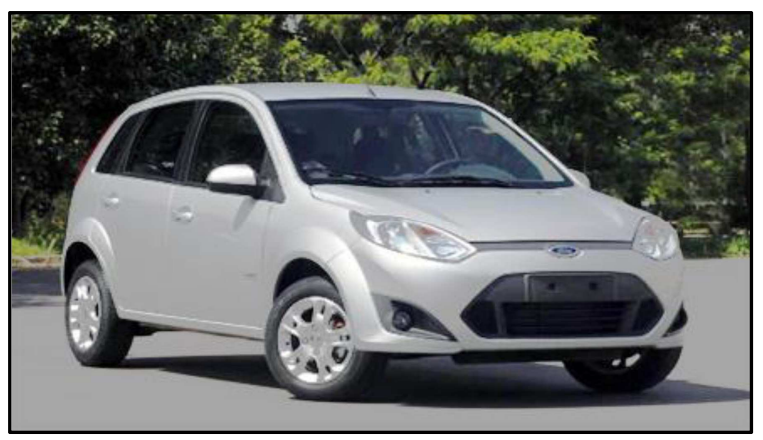

Figure 2. Ford Fiesta in Brazil.

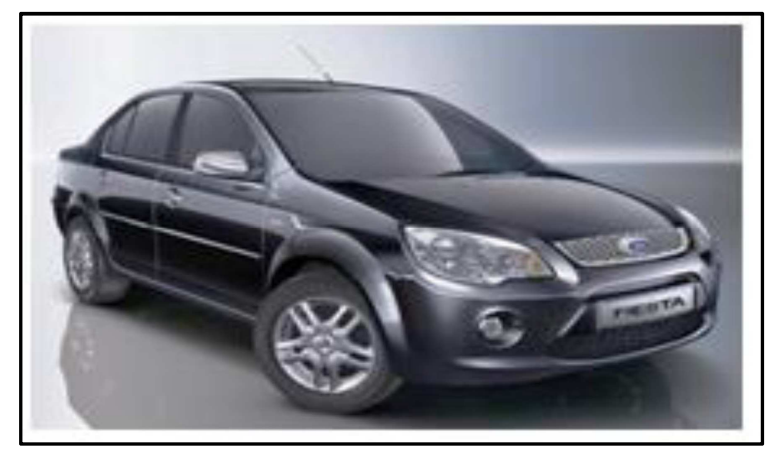

Figure 3. Ford Fiesta in India.

\section{Emotional Response}

User's emotional response is an expression of his emotional reaction towards a product or an incentive. It comes in verbal, emotional and dynamic forms [7].

In industrial design, developing a product to create emotional responses is considered a way to attract users and gain their trust about that product which will fulfill their expectations. Therefore, studies of analyzing users focus on the emotional side instead of focusing on technological features. As the first impression and pleasure of easy usage significantly influence the decision of buying the product.

The industrial design in the third millennium focuses on capturing the emotional needs of users. Integrating these needs into the design process. And obtaining a product that excites users through guaranteed pleasure while interacting with the product at all levels of interaction. It also focuses on the impact of the culture on user's emotions during interacting with the product.

\subsection{Culture Impact on User's Emotional Response}

Emotional expressions such as happiness, sadness, anger, fear, disgust, surprise, etc. are universal phenomena influenced by culture. Therefore, culture might be the necessary frame for researchers to understand the variance in emotional expressions. Social psychology experts assert that emotional response isn't simply a physiological condition. But instead, it is influenced to a large extent by the surrounding cultures and educational experiences. Hence, 
culture affects the emotional responses in terms of the situations that urge a response and the way to express it. Emotional responses are defined in three ways as follows:

a) A certain situation that a person understands according to his experiences.

b) An internal response to that situation, including physical, physiological and mental changes.

c) External physical changes acquired by the culture to express this response, it might be in the form of linguistic expressions, facial features expressions, physical movements or all together.

A number of researchers referred to the relationship between culture and emotional expressions [6], for example:

a) The Japanese identification of anger is inferior to the American, Hungarian, Pole, and Vietnamese. (Biehl \& Matsumoto, 1997)

b) People of various cultural backgrounds differ in terms of their identification and control of emotions. (Biehl, 1997)

c) John Gruber argues that culture is one of the factors that affect emotional responses alongside with other factors such as personality, situation and physical status, figure 4 .

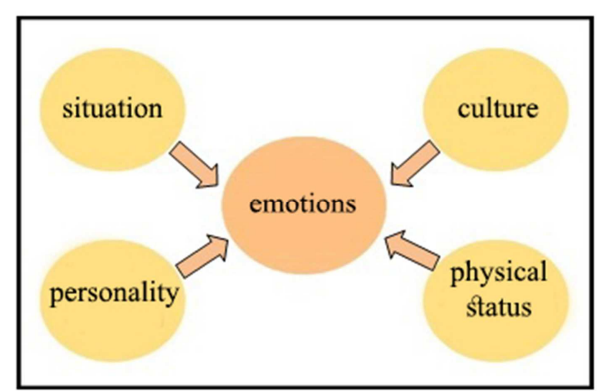

Figure 4. Factors that affect emotional responses.

d) Ashish Gupta illustrates the importance of user's cultural background in affecting and causing emotional responses alongside user's priorities and product's elements (form, color, texture, ......) [2], figure 5.

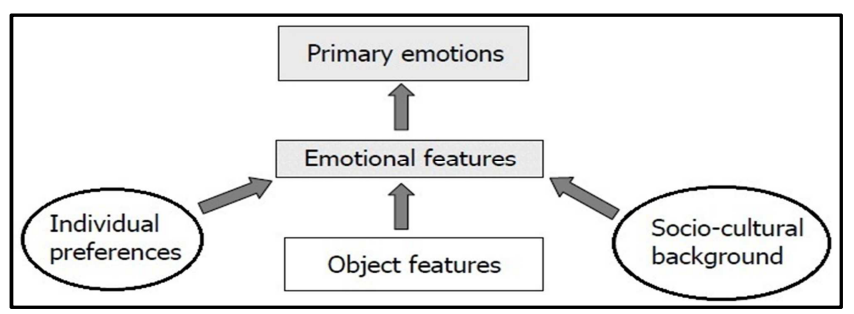

Figure 5. Culture background affects emotional responses.

\subsection{Case studies}

\subsubsection{Telephone Kiosks}

Beijing is a famous city for many different nationalities of the world, the Telephone Kiosks in the streets used by many people. A comparison was made between a number of local residents and some foreign tourists to know the emotional responses towards this product, figure 6 .

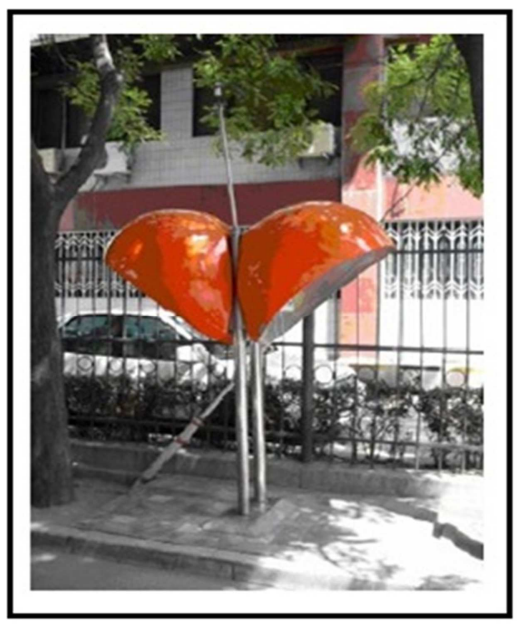

Figure 6. Telephone Kiosks.

The views of local interviewees [6]:

Arousal level: Seven out of ten people said they usually notice the Kiosks, and six people said the color was bright and shiny and the product had a distinctive shape.

Happiness level: Five people were impressed with the design and said it was fun, and two said the design reflected Beijing's cultural habits, and three people said they were pleased when using the product.

The views of foreign people:

Arousal level: Eight out of ten people said they usually notice the Kiosks, and six people mentioned it as shiny and recognizable, and two mentioned that it is not wonderful and inconsistent.

Happiness level: Five people did not like the design and said that its shape is not in line with the surroundings, and it did not embody the cultural habits of the city of Beijing. On the other hand, three people said they liked the telephone Kiosks.

\subsubsection{Coffee-Maker}

In this experiment, the participants (Japanese, Europeans) were asked for their emotional responses to the appearance of the coffee maker, figure 7 . Each person was given a sheet to select his/her response while looking at and using the coffeemaker. The results of this experiment as followings, figure 8: $66 \%$ of the users selected negative emotions. On the other hand, $17 \%$ of the users chose positive emotions and $17 \%$ of the users selected neutral.

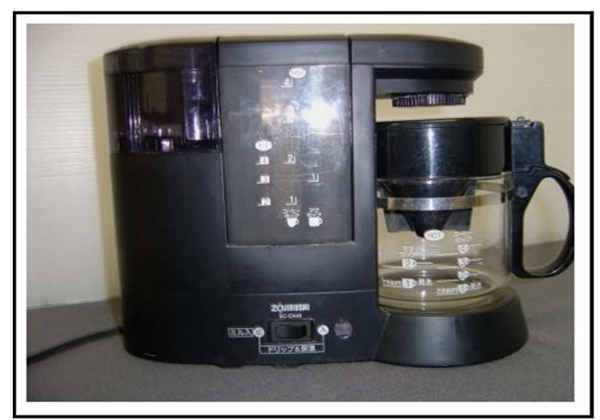

Figure 7. Coffee-Maker. 


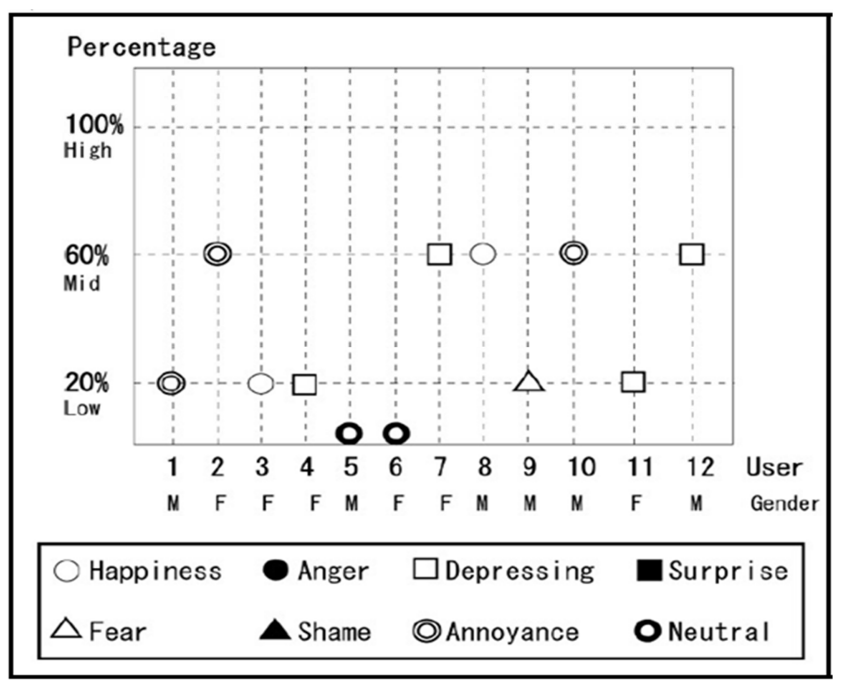

Figure 8. Aesthetics and Users' Test.

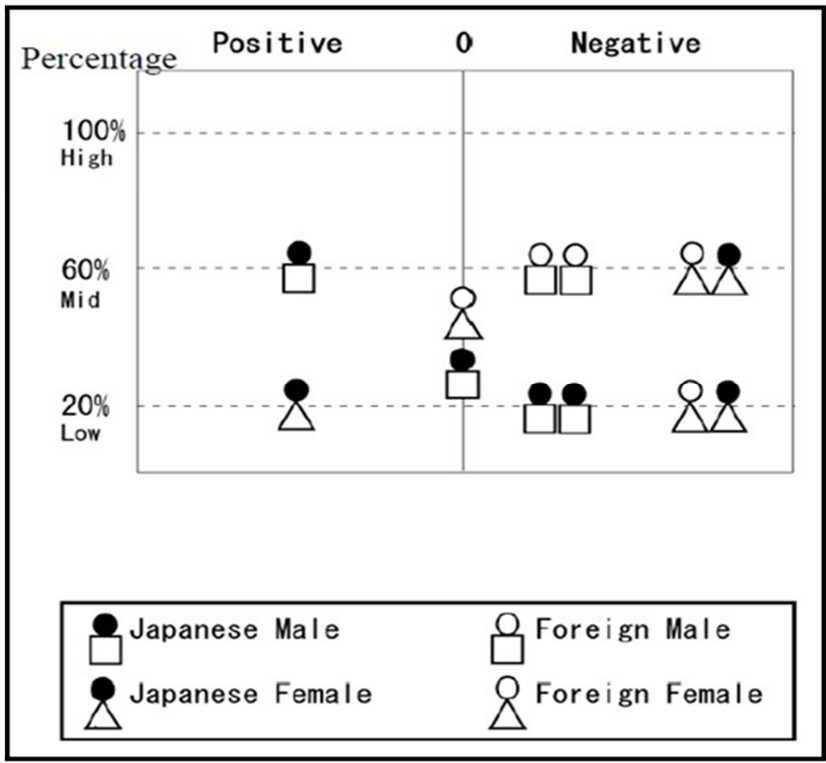

Figure 9. Evaluations of Users'

The results of this experiment showed that the coffee maker's design (form, size, material, texture, and color) is less pleasant for Europeans than Japanese users, figure 9. The appearance of the coffee maker is more favorable among
Japanese users than Europeans [8].

\section{List of Considerations for Designing Products with Taking into Account User's Culture Components}

These considerations provide a guideline tool for industrial designers during the designing process. This list considers the user during the interaction with the product in order to urge the desired emotional responses. (The Appendix)

\section{Results}

The user's emotional response is influenced by the cultural framework within the society in which he lives. The emotional response differs when comparing two different cultures.

The cultural level of users and the community culture of the society in which users live are the most important points that greatly affect the extent of acceptance, the satisfaction of this product and the extent to which happiness is achieved.

\section{Conclusions}

The impact of the message directed through the product depends primarily on the user's connotations and meanings. They stem mainly from its cultural background, so the cultural background of the target user must be taken into account in the design of the product addressed to the user.

It is important to take into account the fact that the appropriateness of design for cultural concepts is one of the considerations that affect the satisfaction of the user's emotional satisfaction, which has become a major target for users.

\section{Appendix}

A Proposal checklist is designed to assure positive emotional response in view of cultural components, table 1 .

Table 1. Proposal checklist for industrial designers.

Culture features
Inspiring the design from the unique cultural elements of the targeted society.
Integrating between user's physical and psychological needs.
Matching between semantics and languages of the product and culture of the user.
Avoiding any conflict or offense to user's culture which would efface his cultural identity.
Fulfilling user's expectations while using the product by involving the user in the development and design processes.
The product should reflect some moral values that match user's culture.
Designing in a way that shifts the culture from a generation to another.
The product has the ability to achieve its purposes according to the environmental circumstances within the targeted society.
Avoiding products that are difficult to use and need high mental effort to understand how to operate, or large physical effort to get their benefits especially
in societies that lack lots of possibilities and grown-up members.
Symbols
Using clear symbols that are easy to understand and common in user's culture.
Matching symbols and displays standards.
Preserving a relationship between the symbol and what it refers to.


Considering user's cognitive ability to understand the symbols and displays.

Designing symbols displays with taking into account the surrounding environment.

Language

Considering society's preferences when sitting a certain type of font.

Using the mother tongue of the user to be easily realized.

Matching between font size and interface size, as well as font color and background colors to guarantee clarity. Making sure there is a suitable space between words and letters.

Habits

Designing with the consideration of the habits of the targeted society.

Matching between the product's interface and the user's using habits.

\section{Traditions}

Designing with the consideration of the traditions of the targeted society.

Norms

Designing with the consideration of the norms of the targeted society.

Values

Designing with the consideration of the different kinds of values within the targeted society.

Using untraditional alternatives for power sources / raw materials through the available options and possibilities of the society.

Considering affordable prices for users.

Avoiding any kind of conflict or offense to the history of the targeted society.

The possibility to inspire a product design from the historical component of the society in order to achieve intellectual and social pleasure.

Avoiding any kind of conflict or offense to any kind of religious beliefs of the targeted society.

The possibility to design products that represent some unique religious factors for the different societies to achieve social pleasure.

Matching between the product technological enhancements and the user education and experience level.

Considering the political authorities impact on users technological experiences.

\section{Way of thinking}

Harmonizing the product operation methods and usage methods with the user expectation way of thinking.

The product should provide help for users to develop their way of thinking.

Avoiding any conflict between the product and the social laws.

\section{User interface}

Focusing on designing the interface first, then the operating mechanism.

Avoid focusing on technology and making it the hub of everything.

Avoiding finishing the interface design without understanding the actual task of it.

Getting usage advantage easily as long frequently using the product.

Identifying the purpose of the product, and the kind of problems it could contribute to overcoming.

Finishing tasks with high accuracy that helps users achieve their goals.

Avoiding any failure while trying to finish the task.

Ability to finish tasks without big mental effort.

Finishing tasks in short amount of time.

Convincing users while using the interface to get what they want.

Good interface size with the optimum distribution of the usage elements.

Displaying information in an eye-comfortable way.

The product has the ability to avoid errors

The product has the ability to well-restoring the work in case of making errors.

Finding solutions to the problems without needing much time.

The product has the ability to perform any task whether it is easy or difficult.

Avoiding lack of information or having difficult information to understand.

Form

Obtaining the desired emotional response from the product form with taking into account the user's aesthetical standards.

Matching between the product appearance and its cultural goals such as shifting/quoting cultural elements.

Matching between the product form, its cultural significance and its purposes.

Suitable product form for the user's customs and traditions.

Avoiding any distortion to the targeted society environment.

Avoiding any sharp parts for safety.

\section{Color}

Choosing suitable colors according to users' culture to urge positive emotional responses.

Attractive colors to help users while choosing his options.

Avoiding shining colors that would cause any discomfort while using the product.

Material

Choosing material matched with user's culture to achieve positive emotional responses.

Avoid using harmful materials to the environment.

Texture

Depending on surface processing methods that match the targeted culture.

Using the texture that achieves positive emotional responses.

Easy to clean texture that avoids dust accumulation 


\section{References}

[1] Ahmed Mohammed M. Abdelrazik: Cultural Variables And Their Impact On The Furniture Design Process In The Era Of Globalization, Braunschweig University of Art, Ph.D., Germany, 2015.

[2] Amaresh Chakrabarti, and Ashish Gupta: Design For Emotions, the international Conference On Engineering Design, 2007.

[3] Amaresh Chakrabarti: Theory, Research Methodology, Aesthetics, Human Factors and Education, Springer, India, 2015 .

[4] Fekry Gamal, AbdElnaby Abo Elmagd, and Tamer Yousif: Usability: Users' Perspective on the Product, International Journal of Advanced Scientific and Technical Research, volume 7, 2015.

[5] Hui Yun Yen, Po Hsien Lin, and Rungtai Lin: Cognition and Product Design Features of Emotional Branding, the international conference on kansei engineering and emotion research, 2014.

[6] Kin Michael and Hongsong: street Furniture design crosscultural Study on emotion design, Design Principles And Practices: An International Journal, Volume 4, No. 1, 2010.

[7] Mona Khader Abbas: The aesthetic response and its relationship to the personality traits of students of the Faculty of Fine Arts / Babylon University, Journal of the Babylon Center for Human Studies, Volume 2, No. 1, 2012.

[8] Nermin Elokla, Yasuyuki Hirai, and Yoshitsugu Morita: Design \& Emotion: A Proposal for Measuring User's Kansei, International Association of Societies of Design Research (IASDR09), Korea, 2009.

[9] P. L. Patrick Rau: Cross-Cultural Design Cultural Differences in Everyday Life, Springer, USA, 2013.

[10] Pratap Kalenahalli Sudarshan, Matthias Wagner, Olesja Marinets, and Michaela Kauer: Identification of User Perceptions and Design Parameters of Vehicle Cluster Instruments in Different Cultures, Springer, 2015.

[11] ZakiaBinte: Cross-cultural impact on marketing strategies: A study on automobile industry, International conference on business, Thailand, 2014.

[12] ZuridaIshak, AzizahJaafar, and Azlina Ahmad: Interface Design for Cultural Differences, Elsevier, Volume 65, 3 December, 2012. 